\title{
Physiotherapists' perception of a community-based primary healthcare clinical education approach to undergraduate learning
}

\author{
S Blose, ${ }^{1}$ MPhysio, BPhysio; N C T Chemane, ${ }^{1}$ MPhysio, BPhysio; V Chetty, ${ }^{1}$ PhD (Health Sciences), MPhysio, BPhysio; \\ P Govender, ${ }^{2} \mathrm{PhD}$ (Health Sciences), MOT, BOT; S Maddocks, ${ }^{1}$ MPhysio, BPhysio \\ ${ }^{1}$ Department of Physiotherapy, School of Health Sciences, University of KwaZulu-Natal, Durban, South Africa \\ ${ }^{2}$ Department of Occupational Therapy, School of Health Sciences, University of KwaZulu-Natal, Durban, South Africa
}

Corresponding author:VChetty (chettyve@ukzn.ac.za)

\begin{abstract}
Background. South African health systems are challenged by numerous stressors, such as a lack of resources, staff shortages and overburdened public sector demands. This necessitates appropriately equipped and trained healthcare professionals to meet the demands of this system. Community-based primary healthcare (PHC) clinical education is an approach towards preparing health science students to meet these demands. Clinical education is the cornerstone of undergraduate training. Physiotherapists are among the healthcare professionals who require undergraduate training that drives competence for independent practice.

Objective. To explore the perceptions and experiences of physiotherapists as clinical supervisors within a physiotherapy undergraduate programme that adopted a community-based PHC approach to clinical training.

Methods. An explorative qualitative approach was used, with semi-structured interviews with 10 purposively selected physiotherapists supervising students on the newly introduced platform. Data were transcribed and analysed using content analysis.

Results. Seven themes emerged from the data, which relate to curriculum redress, organisational factors, stakeholder dynamics, barriers and enablers to decentralised clinical training, perceived preparedness for practice and recommendations.

Conclusions. As the need for an increasing number of health professionals is realised, more innovative methods for clinical education of undergraduate health science students are required. Community-based PHC training for physiotherapy students is one such approach and was generally perceived as a valuable framework to incorporate competencies required for practice as future independent practitioners. Furthermore, improved communication between students, clinicians and academic staff was seen as a recommendation to influence clinical education.
\end{abstract}

Afr J Health Professions Educ 2019;11(1):16-21. DOI:10.7196/AJHPE.2019.v11i1.1046

The dynamic transitions in healthcare systems globally necessitate the training of healthcare professionals who are responsive to the needs of the community that they serve to ensure quality and relevance of care. ${ }^{[1]}$ Undergraduate clinical education is therefore critical for the development of socially competent graduates who are equipped with technical skills and insight to function purposefully within these changing social and health contexts. $^{[2]}$ Students' clinical competence, proficiency and aptitude are core to their clinical education and training, which should be rooted in a competency-based undergraduate programme. ${ }^{[3-5]}$ In South Africa (SA), the gaping disparity in health provision between the over-accessed public health facilities and well-resourced private healthcare settings prompted government to introduce the National Health Insurance (NHI), with the incorporation of the primary healthcare (PHC) approach. ${ }^{[6,7]} \mathrm{NHI}$ is a government funding model that ensures disenfranchised communities access to quality healthcare. Through NHI, PHC has proposed re-engineering focused on prevention of diseases, promotion of health and ensuring availability of rehabilitative services at community level. PHC is a strategy to ensure that healthcare services are available in resource-scarce communities, but the uptake in healthcare systems nationally remains poor. ${ }^{[8]}$ Innovative approaches of actualising the implementation of the ideal PHC model are necessary to influence the disparity in public v. private healthcare in SA. ${ }^{[8]}$ Perpetuating the vision for NHI, the University of KwaZulu-Natal (UKZN)
College of Health Sciences (CHS), in collaboration with the KwaZuluNatal (KZN) Department of Health (DoH), embarked on the roll-out of community-based training within a PHC (CBTPHC) approach. ${ }^{[9]}$ UKZN adopted this approach to equip health science students with the necessary skills to serve communities in dire need of healthcare. For the purpose of this article, we refer to this method of training as decentralised clinical training (DCT).

This study focused on the discipline of physiotherapy within the CHS at UKZN, which offers a 4-year undergraduate degree programme with a professional qualification (Bachelor degree). There is a greater theoretical bias in years 1 and 2, with a deliberate shift to clinical training and competency development in years 3 and 4 of study. Intake varies between 50 students in year 1 and up to 55 students in the final year, depending on the throughput of students during the programme. For 2017, final-year students were introduced to the DCT framework in which they were placed at urban, rural and peri-urban sites in KZN Province, where they were predominantly under the care and supervision of physiotherapy clinicians at the respective settings. The facilities provided them with clinical exposure to neurological, cardiopulmonary and neuromusculoskeletal conditions and communitybased rehabilitation. Each physiotherapy student spent 5 weeks at 4 of the clinical sites, 2 of 6 newly introduced settings that were rural/peri-urban and 2 urban facilities that were used prior to the new CBTPHC approach. Before 
the commencement of DCT, participating physiotherapists were invited to attend preclinical supervision workshops at the university. The workshops aimed to equip the physiotherapist employed at the healthcare facilities on the DCT platform with teaching and learning competences, as well as supervisory skills to influence learning outcomes for undergraduate students.

Mostert-Wentzel et al. ${ }^{\left[{ }^{[3]}\right.}$ in their study of the status of undergraduate community-based and public health physiotherapy education in SA, found that while community physiotherapy curricula address the health profile of the population and priorities in the health system to different degrees, gaps in preparing physiotherapy students for the needs of the SA population were highlighted. DCT as a vehicle could possibly respond to this need, as it allows for preparation of health science students via training at these decentralised clinical facilities that are primarily based in rural or peri-urban communities and are in keeping with the PHC approach. Implementation of DCT, however, requires careful consideration of a number of factors, such as clinical site organisational structure, student attitudes, clinician attitudes and exploration of curriculum implications.

A current flaw in the roll-out of DCT in the CHS at UKZN is the lack of a working clinical training model to facilitate such a novel approach. In this article, we report the findings of a study that explored the perceptions of physiotherapists as clinical supervisors in the novel DCT programme in the study context. The understanding of participating physiotherapists' perceptions aids in the development of an integrated model of clinical training by valuable insight into their role and recommendations for teaching and learning. This study forms part of a larger study that is geared towards the development of a model for physiotherapy clinical education, which will feed into an overall model for health professions education within DCT platforms for the CHS at UKZN. ${ }^{[10]}$

\section{Methods}

A qualitative study approach ${ }^{[11,12]}$ was employed to explore the perceptions of physiotherapists supervising undergraduate physiotherapy students in a DCT approach. Ten physiotherapy clinical supervisors employed by the $\mathrm{DoH}$ in public sector facilities across peri-urban and rural settings on the DCT platform were purposively selected. Only qualified physiotherapists, currently registered with the Health Professions Council of South Africa (HPCSA) for 2017 - 2018 and actively involved in clinical supervision of students, were included in the study. The use of qualitative research allowed for in-depth exploration of the perceptions and experiences of these physiotherapists as clinical supervisors to inform the future planning and review of the novel clinical training approach within this setting.

\section{Study setting}

The study was done in KZN, SA, on 6 clinical training platforms, i.e. Murchison Hospital (rural), Port Shepstone Hospital (peri-urban), G J Crookes Hospital (peri-urban), Newcastle Hospital (peri-urban), Madadeni Hospital (rural) and Ngwelezane Hospital (rural). The facilities provided exposure to neurological, cardiopulmonary and neuromusculoskeletal conditions and community-based rehabilitation. Students were exposed to traditional institutional care, as well as outreach and PHC facilities.

\section{Ethical approval}

Ethical approval was granted by the Humanities and Social Sciences Research Ethics committee of UKZN (ref. no. HSS/0727/017) and the DoH (ref. no. KZ_201805-007). All participants were recruited on a voluntary basis and informed of their right to withdraw from the study at any time. They also gave informed consent. Anonymity was ensured by allocating pseudonyms to clinical supervisors when reflecting quotes. ${ }^{[13]}$

\section{Data collection}

Following ethical approval, 10 individual semi-structured interviews were conducted with physiotherapists at the end of the year. A flexible interview guide was developed with open-ended questions encompassing work experience and exposure to student training, and involvement and role of therapists in the implementation of DCT were explored. All interviews were conducted in English. Initial questions were followed up with probing and clarification to gain full understanding of comments and responses during the interview. Interviews lasted from $\sim 45$ minutes to 1 hour and were audiorecorded with field notes by the principal author. A moderator was present at each interview, together with the principal author. ${ }^{[14]}$

\section{Data analysis}

The recorded data were transcribed verbatim and verified for accuracy against the audio-recordings by the principal author and moderator. Transcriptions were forwarded to participants as a strategy for member checking to ensure that opinions were accurately captured in the analysis. Data were read and re-read for familiarisation to obtain an in-depth understanding of the content. The principal author and moderator performed separate data coding to enhance trustworthiness of the findings. Thematic analysis was used to identify emerging themes and subthemes. Similarities and differences in the coding were disputed until consensus was reached. ${ }^{[11,15,16]}$

\section{Results}

The demographic profile of participants is presented in Table 1. The results of the study are premised on the 7 overarching themes, highlighted in Table 2.

\section{Discussion}

The theme of curriculum redress includes the following subthemes: theory into practice, PHC integration and community-based rehabilitation strategy. The participants believed that the undergraduate physiotherapy curriculum required review, and issues remained with regard to integration of theory into clinical practice. A recent study in the same context revealed that physiotherapy students were of the opinion that there were curriculum disparities in terms of content and fluidity, which were believed to be integral to transformation of classroom teaching to practice. ${ }^{[3]}$ Recent studies in similar contexts also reflect the need for healthcare professional programmes to be dynamic and move towards the needs of healthcare systems. ${ }^{[17-19]}$ The integration of community-based approaches to teaching is crucial in preparing socially and culturally competent physiotherapy students to offer the relevant care. ${ }^{[20,21]}$ The participants in this study believed that this approach allowed students to gain insight into communities, enabling a better understanding of those in their care. ${ }^{[18,20]}$ However, alignment of the curriculum to community needs remains key to physiotherapy students being adequately prepared for clinical practice. ${ }^{[3,17,18,22,23]}$

\section{Organisational factors}

This was a resounding theme and included poor infrastructure and lack of resources and equipment as subthemes. Inadequate infrastructure remains 
Table 1. Demographic characteristics of physiotherapists

\begin{tabular}{|c|c|c|c|c|c|c|c|c|}
\hline $\begin{array}{l}\text { Participant } \\
\text { pseudonym }\end{array}$ & $\begin{array}{l}\text { Age, } \\
\text { years }\end{array}$ & Gender & Race & $\begin{array}{l}\text { Clinical } \\
\text { experience, } \\
\text { years }\end{array}$ & $\begin{array}{l}\text { Clinical super- } \\
\text { vision experience, } \\
\text { years }\end{array}$ & Tertiary institute & Context & Type of facility \\
\hline Andrew & 50 & Male & Black African & 20 & 18 & University of Zambia & Peri-urban & $\begin{array}{l}\text { Tertiary/regional } \\
\text { hospital }\end{array}$ \\
\hline Palesa & 43 & Female & Black African & 17 & 1 & University of KwaZulu-Natal & Peri-urban & Specialised hospital \\
\hline Priya & 36 & Female & Indian & 14 & 13 & University of KwaZulu-Natal & Peri-urban & District hospital \\
\hline Thandi & 36 & Female & Black African & 13 & 8 & University of KwaZulu-Natal & Peri-urban & Regional hospital \\
\hline Gugu & 37 & Female & Black African & 11 & 10 & University of KwaZulu-Natal & Peri-urban & Regional hospital \\
\hline Thembeka & 30 & Female & Black African & 8 & 4 & University of KwaZulu-Natal & Rural & District hospital \\
\hline Gloria & 30 & Female & Black African & 8 & 3 & University of KwaZulu-Natal & Peri-urban & $\begin{array}{l}\text { Tertiary/regional } \\
\text { hospital }\end{array}$ \\
\hline Tanya & 28 & Female & Mixed & 7 & 3 & Stellenbosch University & Rural & Regional hospital \\
\hline Rithesh & 26 & Male & Indian & 3 & $7 / 12$ & University of KwaZulu-Natal & Rural & Regional hospital \\
\hline Yolisa & 24 & Female & Black African & 2 & $7 / 12$ & University of Cape Town & Rural & District hospital \\
\hline
\end{tabular}

Table 2. Summary of themes and subthemes with verbatim quotes

Theme 1: Curriculum redress

Theory into practice

'I think I matured in a certain way and also learnt to remove textbook thinking, because the university trains us in such a way that we think in a textbook style; even with patients - we want them to come in textbook style.' (Priya)

'The second group, I thought that they were lacking theoretical knowledge and I had to sit down with them and give them tutorials; and it didn't feel like it was sort of a refresher, it was like the first time they ever heard about such things.' (Tanya)

PHC integration

'You trained in urban facilities and graduated there, then you come to a rural hospital where it is something different altogether.' (Rithesh)

Community-based rehabilitation strategy 'We have two or three students allocated in the community, which is good because there is a lot they can do for the community. We take them on home visits and to clinics, and one group trained the healthcare team as a community project; they should be taught about this (theory modules) - community caregivers.' (Priya)

Theme 2: Organisational factors

Poor infrastructure 'The department has occupational therapy, speech and audiology here and we don't have space.' (Palesa) 'We felt that our department is very small and we are in a district hospital.' (Thembeka)

Lack of resources and equipment 'We don't have all the equipment but the university has been extra supporting in providing us with equipment (referring to TENS machines, ultrasound and hot packs) that we can use in the department.' (Yolisa) We didn't have the heat packs, ultrasound and infrared, so the university provided that'. (Gloria) We wanted ice and hot packs and they did give them to us. The electrode-cover things - they did give them to us.' (Palesa)

'The driver had a problem with taking students to the clinic and on home visits.' (Thembeka)

'Time is a problem ... tutorials in the afternoon, but sometimes there are many patients.' (Rithesh)

'I was a bit resistant, very resistant, thinking about staffing we had, our manager was leaving us in that year. I was busy with my masters, which took a lot of time and was a heavy load; I didn't know how we were going to cope.' (Thandi)

Theme 3: Stakeholder dynamics

Effective leadership roles

'I did speak to my staff about it (manager). I am fortunate that I don't have staff that are resistant to having students here.' (Priya)

'We had to sit down and discuss it (manager to staff). We all agreed that we were willing to help out.'

(Andrew)

Collaboration between academics and clinical 'If lecturers can be involved more, at least once a week or month, they can pop in once or twice before the supervisors exams. They must not just come when it's an exam.' (Palesa)

'I wish in January or February when they attend lectures we can be there so we can learn. Because there are many challenges. We are always not sure if you are giving them the right thing. I think it is me who is feeling inferior.' (Gloria)

Partnership between student and clinician 'Students are not the same, some are willing to learn and some need to be pushed.We worry about if we give them enough supervision. It is our duty to guide them and mentor. We took a stand as a department that we will support DCT, but they need to want to learn'. (Palesa)

Continued ... 


\begin{tabular}{|c|c|}
\hline \multicolumn{2}{|l|}{ Theme 3: Stakeholder dynamics } \\
\hline Community-service therapists and students & $\begin{array}{l}\text { 'The community-service therapists were giving more patients to the students in the ward ... they would fight } \\
\ldots \text { they were sort of bullying the first group.' (Yolisa) }\end{array}$ \\
\hline \multicolumn{2}{|c|}{ Theme 4: Barriers to decentralised clinical training } \\
\hline Communication and technology issues & $\begin{array}{l}\text { 'I know that some constraints that the students brought to us is that they didn't have access to materials, in } \\
\text { terms of getting a modem or data.' (Rithesh) }\end{array}$ \\
\hline Student attitudinal barriers & $\begin{array}{l}\text { 'They didn't want to learn as well. Even if you give them a patient, OPD patient, they change their facial } \\
\text { expression. They were lazy, the first group was bad, even their feedback at the end of the block.' (Gloria) } \\
\text { 'They were not happy, the students were not communicating with us as clinical supervisors.' (Thembeka) }\end{array}$ \\
\hline \multicolumn{2}{|c|}{ Theme 5: Enablers to decentralised clinical training } \\
\hline Rural v. urban clinical education & $\begin{array}{l}\text { 'They have exposure to rural facilities, comparative to the facilities in the city. They see a different } \\
\text { environment, a different setting that will prepare them for when they become professionals and they are } \\
\text { qualified, instead of being thrown in at the deep end of rural lifestyle or a rural setting.' (Rithesh) }\end{array}$ \\
\hline \multirow[t]{2}{*}{ Personal growth } & $\begin{array}{l}\text { 'I feel that I've grown since the first group. In the first group it was quite daunting for me because they } \\
\text { would ask questions and I really had to think about it. But now I feel that I am confident, I can answer their } \\
\text { questions to the best of my ability.' (Tanya) }\end{array}$ \\
\hline & $\begin{array}{l}\text { 'The students help stimulate staff. The stimulation is that as clinical supervisors we are always kept on our } \\
\text { toes because we have to be ready when students ask questions and stuff.' (Priya) }\end{array}$ \\
\hline Students preclinical training & $\begin{array}{l}\text { 'It's a block that they have already done in third year and I assume they had more supervision than the first } \\
\text { time around.' (Yolisa) }\end{array}$ \\
\hline \multirow[t]{2}{*}{ Student impact } & 'Students help us a lot and some people wouldn't want to admit it.' (Rithesh) \\
\hline & 'We have more helping hands in the department.' (Yolisa) \\
\hline \multicolumn{2}{|c|}{ Theme 6: Perceived preparedness for clinical supervision } \\
\hline \multirow[t]{3}{*}{ Clinical practice experience } & 'This is the first time I am working with students. I have no previous experience working with students.' (Yolisa) \\
\hline & $\begin{array}{l}\text { 'Almost every year we had elective students that I had to supervise. When I was in, we were actively involved } \\
\text { in supervising students.' (Priya) }\end{array}$ \\
\hline & $\begin{array}{l}\text { 'Clinical supervision is a learning process. It's a continuous learning process. Supervising community-service } \\
\text { therapists also helped me this year.' (Gugu) }\end{array}$ \\
\hline \multirow[t]{2}{*}{ Preclinical supervision workshops } & 'The workshops they had on campus (referring to preclinical workshops offered by the university).' (Yolisa) \\
\hline & $\begin{array}{l}\text { 'I've attend some of the meetings and I attended the training (referring to preclinical workshops offered by the } \\
\text { university). So, all of us at the department we quite hands-on with the students that come here, although they } \\
\text { are here for a more independent block, they are here for the community block; so we really only supervise } \\
\text { them when they are on the hospital premises and then they would be working on their projects.' (Gugu) } \\
\text { 'We also attended all the meetings called upon by the university towards when they introduced the training } \\
\text { from the start until the end ... First meeting that we had to assess and I think to give us what was expected, } \\
\text { and while they're willing to help us in terms of equipment and whatever material that is needed here ... we } \\
\text { were willing to help in terms of whatever outcomes were set out.' (Andrew) }\end{array}$ \\
\hline
\end{tabular}

7: Recommendations

Improved collaboration

Recruitment of local clinical supervisors

Improved information and communication systems

Academic incentives
'Their supervisors and clinical staff need to come together, not only to assess students but to also have patient presentations to improve knowledge.' (Palesa)

'The academic staff cannot do much about the fact that there are no part-timers, but one recommendation is that having part-time staff locally will make much difference in the DCT; it will actually help students and the academic supervisors because I don't think they can spread themselves all around.' (Priya)

'If they had an online tutorial that they could do on a daily basis - because they don't see patients the whole day'. (Tanya)

'If the university also had set up online access to learning material and lectures; that would help us here to teach.' (Thandi)

'If there could be some form of incentives that can be done, it could be in a form of learning courses, remember we are continuously learning every day... ? (Priya)

PHC $=$ primary healthcare; TENS $=$ transcutaneous electrical nerve stimulators; $\mathrm{DCT}=$ decentralised clinical training; $\mathrm{OPD}=$ outpatient department.

an organisational limitation in SA healthcare systems. ${ }^{[8,20,24-27]}$ Evidence from other studies concurs with findings in this article in terms of transport and equipment limitations that remain a barrier to optimal care in rural and peri-urban healthcare facilities. ${ }^{[3,24,25]}$ Rural health facilities are understaffed and there is a continuous exodus of clinicians into private sector or urban-based facilities. ${ }^{[19,28-30]}$ Stiller et al., ${ }^{[31]}$ in a 2004 study, postulate that healthcare staff juggle high patient demands and administrative duties, which contend with participation in clinical education. However, De Villiers et al., ${ }^{[26,27]}$ in recent studies in SA, reported that approaches such as decentralised clinical training can address such incongruences in 
healthcare systems. Moreover, there is the notion that students who train at rural sites are more likely to accept employment at such sites. ${ }^{[9,27]}$

\section{Stakeholder dynamics}

This theme included effective leadership roles, collaboration between academics and clinical supervisors, the relationship between students and clinicians, as well as community service therapists as subthemes. The role of physiotherapy managers in the clinical education approach is crucial for success of student learning. ${ }^{[27,29]}$ Furthermore, communication and ongoing collaboration between students, academics and supervising physiotherapists are imperative in this process. ${ }^{[32]}$ Collaborative preparation and planning prior to the commencement of DCT is believed to be of importance. ${ }^{[19,28]} \mathrm{A}$ study by Lo et al. ${ }^{[33]}$ reveals that a working partnership between academic staff and clinicians promotes future collaboration. The partnership between student and supervising therapist is also important and aids in creating a mutual beneficial learning environment for effective training in technical skills, core competencies and ethical and social integration into clinical practice. A concern voiced in this study was the poor partnership at a site between the community service officer (CSO) or therapist and students. Junior staff, such as CSOs, viewed as support 'buddies' for students, rather than clinical supervisors, have been cited. ${ }^{[29]}$ Other studies on the placement of students cite clashes between students and clinicians due to personality conflicts. ${ }^{[28,29]}$

\section{Barriers}

Barriers to DCT included communication and technological issues, as well as student attitudinal barriers as subthemes. Technology and communication access in the DCT sites posed barriers to learning, as students were unable to access information. ${ }^{[24]}$ There has been a surge in the use of technology as a method to enhance learning; ${ }^{[34]}$ however, efforts are required towards improving access to optimise this tool in resource-limited settings. In this study, student attitudinal barriers were also believed to inhibit optimal learning. ${ }^{[35]}$

\section{Enablers}

Enablers to DCT included the subthemes rural v. urban clinical education, personal growth, students' preclinical training and student impact. Physiotherapy supervisors were motivated and found it rewarding to work with students, ${ }^{[28]}$ in addition to personal growth in the supervision process and becoming increasingly confident as time progressed. Further personal development included physiotherapists updating their clinical knowledge and skills to be of value to students. ${ }^{[28,29]}$ The preclinical training of students prior to embarking on DCT was identified as key in preparation for clinical practice. ${ }^{[18]}$ Students were seen as added personnel and other studies corroborate that students can alleviate the high burden of staff and relieve workload pressure. ${ }^{[1]}$

\section{Perceived preparedness of physiotherapists}

Within the theme of perceived preparedness of physiotherapists for clinical supervision, clinical practice experience and preclinical supervision workshops were identified as subthemes. Most physiotherapists indicated that, despite their clinical practice experience, they initially felt unprepared to supervise students. Feelings were attributed to change in the curriculum and teaching pedagogy and lack of personal confidence. Similar feelings were expressed by clinicians involved in supervision of occupational therapy students, who felt that they had not been suitably prepared and were anxious about judgement by students. ${ }^{[36]}$ There was a perceived preparedness of physiotherapists who had experience in supervision of students during clinical elective rotations with students from other SA tertiary institutions during their vacation, as well as exposure to communityservice physiotherapists at the respective healthcare facilities. Furthermore, a preclinical supervision workshop offered to supervising physiotherapists appeared to offer them respite in their perception of unpreparedness. ${ }^{[29,37]}$

\section{Recommendations}

Finally, recommendations identified in this study included improved collaboration, improved information and communication systems, recruitment of local clinical supervisors and academic incentives. Physiotherapists emphasised the need for improved communication between academics and clinicians. This was in keeping with findings in other studies, where communication between stakeholders was an enabler to improved clinical education approaches. ${ }^{[19,38]}$ A SA study that explored an undergraduate physiotherapy programme highlighted that communication between academics and clinicians supervising physiotherapy students is a facilitator of clinical education and preparedness for practice. ${ }^{[17]}$ Good communication between academic staff and clinicians provides a seamless learning environment for student learning. ${ }^{[38]}$ Recruitment of private sector physiotherapists as clinical supervisors was recommended as respite for the overburdened hospital staff who supervise students. ${ }^{[28]}$ Campbell et al. ${ }^{[39]}$ reported that a direct relationship must be built with local community members, healthcare services and health professional education institutions. ${ }^{[39]}$ Online platforms were also recommended to enhance clinical education, which is aligned to current trends in undergraduate health professions education. ${ }^{[40]}$ A further recommendation included the offering of academic incentives in the form of continuous professional development courses, as well as tuition remission for postgraduate courses.

\section{Study limitations}

The study was limited to 6 new DCT placement sites for one tertiary institution. Moreover, the number of clinical supervisors was limited to those who were directly involved in the supervision of students during the pilot year and represented subjective reports of their experiences. The results should therefore be interpreted with caution and may not be generalisable.

\section{Conclusion}

As the need for increasing the number of health professionals to respond to the current health needs of the country is realised, more innovative methods for the clinical education of health science students are required. CBTPHC is an option that allows students to be exposed to PHC in rural and underserved communities. However, for this platform to become an enabling clinical training environment and to ensure success, the voices of essential stakeholders are necessary. This study sought to explore the perceptions and experiences of physiotherapists as clinical supervisors within the CBTPHC programme. The platform of clinical training for physiotherapy students was generally perceived as a valuable framework to incorporate competencies required for community-based PHC practice. Furthermore, physiotherapists believed that good communication between stakeholders enhances the learning environment and incentives for clinicians, such as academic study fee remissions. Such incentives are mutually beneficial, as these will further enhance the knowledge of physiotherapists who supervise 
students. Further research into the experiences of health science students and academics is key to the development of novel integrated approaches such as CBTPHC in clinical training.

Declaration. The study was in fulfilment of SB's postgraduate degree in the School of Health Sciences, University of KwaZulu-Natal, Durban, SA.

Acknowledgements. The authors acknowledge the physiotherapy clinical supervisors who shared their experiences and insights regarding the study.

Author contributions. SB: principal investigator and responsible for the coconceptualisation, data collection and write-up; VC, NC, PG and SM: assisted in the conceptualisation and supervision, guided data interpretation and assisted in the critical review of the article.

Funding. Funded under the i-DecT Project that received support via a College of Health Sciences, University of KwaZulu-Natal, competitive grant.

Conflicts of interest. None.

1. Frenk J, Chen L, Bhutta ZA, et al. Health professionals for a new century: Transforming education to strengthen health systems in an interdependent world. Lancet 2010;376(9756):1923-1958. https://doi.org/10.1016/s01406736(10)61854-5

2. Allodola VF. The effects of educational models based on experiential learning in medical education: An international literature review. TUTOR 2014;14(1):23-49. https://doi.org/10.3280/erp2013-002005

3. Mostert-Wentzel K, Frantz JM, van Rooijen T. Status of undergraduate community-based and public-health physiotherapy education in South Africa. S Afr J Physiother 2013;69(1):26-35. https://doi.org/10.4102/sajp v69i1.369

4. Mostert-Wentzel K, Frantz J, van Rooijen AJ. A model for community physiotherapy from the perspective of newly graduated physiotherapists as a guide to curriculum revision. Afr J Health Professions Educ 2013;5(1):19-25. https://doi.org/10.7196.203

5. Lardinois KL, Gosselin D, McCarty D, Ollendick K, Covington K. A collaborative model of integrated clinical education in physical therapist education: Application to the pediatric essential core competency of familycentered care. J Phys Ther Educ 2017;31(2):131-136. https://doi.org/10.1097/00001416-201731020-00015

6. South Africa. Department of Health White Paper: National Health Insurance. 2015.

6. South Africa. Department of Health White Paper: National Health Insurance. 2015 .
7. South African Government. Primary health care re-engineering. https://www.phasa.org.za/wp-content/.../11/ 7. South African Government. Primary health care re-engineering. ht
Pillay-The-implementation-of-PHC.pdf (accessed 12 February 2019).

8. Kautzky K, Tollman SM. A perspective on primary health care in South Africa: Primary health care in context. S Afr Health Rev 2008;1:17-30

9. Caldwell RI, Aldous C. The National Health Insurance, the decentralised clinical training platform, and specialis outreach. S Afr Med J 2017;107(1):39-40. https://doi.org/10.7196/SAMJ.2017.v107i1.12008

10. Govender P, Chetty V, Naidoo D, Pefile N. Integrated decentralized training for health professions education a the University of KwaZulu-Natal, South Africa: Protocol for the I-DecT Project. JMIR Res Protoc 2018;7(1):e19. https://doi.org/10.2196/preprints.7551

11. Twycross A. Research design: Qualitative, quantitative and mixed methods approaches. Nurse Res 2004;12(1):82. 12. Creswell JW, Creswell JD. Research Design: Qualitative, Quantitative, and Mixed Methods Approaches. Thousand Oaks, CA: Sage, 2017.

13. World Medical Association. Declaration of Helsinki. Ethical principles for medical research involving human subjects. 2008. www.wma.net/policies-post/wma-declaration-of-helsinki-ethical-principles-for-medical-researchsubjects. 2008. Www.wma.net/policies-post/wma-decla
involving-human-subjects/ (accessed 11 February 2019).

14. King N, Horrocks C. Interviews in Qualitative Research. Thousand Oaks, CA: Sage, 2010

15. Graneheim UH, Lundman B. Qualitative content analysis in nursing research: Concepts, procedures and measure to achieve trustworthiness. Nurse Educ Today 2004;24(2):105-112. https://doi.org/10.1016/j.nedt.2003.10.001
to
16. Saldaña J. The Coding Manual for Qualitative Researchers. 2nd ed. Thousand Oaks, CA: Sage, 2015

17. Talberg H, Scott D. Do physiotherapy students perceive that they are adequately prepared to enter clinica practice? An empirical study. Afr J Health Professions Educ 2014;6(1):17-22. https://doi.org/10.7196/AJHPE.219

18. Ramklass SS. An investigation into the alignment of a South African physiotherapy curriculum and the expectations of the healthcare system. Physiotherapy 2009;95(3):215-222. https://doi.org/10.1016/j.physio. 2009.02 .004

19. Rodger S, Webb G, Devitt L, Gilbert J, Wrightson P, McMeeken J. Clinical education and practice placements in the allied health professions: An international perspective. J Allied Health 2008;37(1):53-62.

20. Ernstzen DV, Statham SB, Hanekom SD. Learning experiences of physiotherapy students during primary healthcare clinical placements. Afr J Health Professions Educ 2014;6(2):211-216. https://doi.org/10.7196/ AJHPE.530

21. Strohschein J, Hagler P, May L. Assessing the need for change in clinical education practices. Phys Ther 2002;82(2):160-172.

22. Krause MW, Vilioen MJ, Nel MM, Joubert G. Development of a framework with specific reference to exit-level outcomes for the education and training of South African undergraduate physiotherapy students. Health Pol 2006;77(1):37-42. https://doi.org/10.1016/.healthpol.2005.07.015

23. Diab P, Flack P. Benefits of community-based education to the community in South African health science facilities. Afr J Prim Health Care Fam Med 2013;5(1). https://doi.org/10.4102/phcfm.v5i1.474

24. Paliadelis PS, Parmenter G, Parker V, Giles M, Higgins I. The challenges confronting clinicians in rural acute care settings: A participatory research project. Rural Remote Health 2012;12(2):2017.

25. Muasya MK, Dienya TM, Wagaiyu EG, Nduati R, Kiarie JN. Capacity of non-tertiary Kenyan health facilities selected for decentralised dental training. East Afr Med J 2016;93(2):55-59.

26. De Villiers M, van Schalkwyk S, Blitz J, et al. Decentralised training for medical students: A scoping review. BMC Med Educ 2017:17(1):196, https://doi.org/10.1186/s12909-017-1050-9

27. De Villiers MR, Blitz J, Couper I, et al. Decentralised training for medical students: Towards a South African consensus. Afr J Prim Health Care Fam Med 2017;9(1):1-6. https://doi.org/10.4102/phcfm.v9i1.1449

28. Moore A, Morris J, Crouch V, Martin M. Evaluation of physiotherapy clinical educational models: Comparing 1: 1, 2:1 and 3: 1 placements. Physiotherapy 2003;89(8):489-501. https://doi.org/10.1016/s0031-9406(05)60007-7 Currens JA, Bithell CP. Clinical education: Listening to different perspectives. Physiotherapy 2000;86(12):645-653 https://doi.org/10.1016/s0031-9406(05)61302-8

30. Crisp N, Chen L. Global supply of health professionals. New Engl J Med 2014;370(10):950-957. https://doi org/10.1056/nejmral111610

1. Stiller K, Lynch E, Phillips AC, Lambert P. Clinical education of physiotherapy students in Australia: Perception of current models. Austr J Physiother 2004;50(4):243-247. https://doi.org/10.1016/s0004-9514(14)60114-8

32. Gassner LA, Wotton K, Clare J, Hofmeyer A, Buckman J. Theory meets practice: Evaluation of a model of collaboration. Academic and clinician partnership in the development and implementation teaching. Collegian 1999;6(3):14-21. https://doi.org/10.1016/s1322-7696(08)60337-6

33. Lo K, Curtis H, Keating JL, Bearman M. Physiotherapy clinical educators' perceptions of student fitness to practise. BMC Med Educ 2017;17(1):16. https://doi.org/10.1186/s12909-016-0847-2

34. Talib Z, van Schalkwyk S, Couper I, et al. Medical education in decentralized settings: How medical students contribute to health care in 10 sub-Saharan African countries. Acad Med 2017;92(12):1723-1732. https://doi. org/10.1097/acm.0000000000002003

35. Bolton D. student attitude and online learning: The impact of instructional design factors upon attitudes toward Bolton D. student attitude and online learning: The impact of instructional design factors upon attitudes toward Distance Learning Experience. Hershey, PA: IGI Global, 2017:307-333.

36. De Witt P, Rothberg A, Bruce J. Clinical education of occupational therapy students: Reluctant clinical educators. S Afr J Occup Ther 2015;45(3):28-33. https://doi.org/10.17159/2310-3833/2015/v45n3/a6

7. Currens JB, Bithell CP. The 2:1 clinical placement model: Perceptions of clinical educators and students. Physiotherapy 2003;89(4):204-218. https://doi.org/10.1016/S0031-9406(05)60152-6

38. McMahon S, Cusack T, O'Donoghue G. Barriers and facilitators to providing undergraduate physiotherapy clinical education in the primary care setting: A three-round Delphi study. Physiotherapy 2014;100(1):14-19. https://doi.org/10.1016/j.physio.2013.04.006

39. Campbell LM, Ross AJ, MacGregor RG. The Umthombo Youth Development Foundation, South Africa: Lesson towards community involvement in health professional education. Afr J Health Professions Educ 2016;8(1):50-55. https://doi.org/10.7196/ajhpe.2016.v8i1.559

40. Rowe M, Bozalek V, Frantz J. Using Google Drive to facilitate a blended approach to authentic learning. Br J Educ Tech 2013;44(4)594-606. https://doi.org/10.1111/bjet.12063

Accepted 12 July 2018. 